\title{
Determining of apoptosis at in vitro conditioned DRG neurons with TUNEL method
}

\author{
Elif KAVAL OĞUZ a,* \\ a Yüzüncü Yll University, Department of Science Education, TR-65080, VAN Turkey
}

\section{ART I C LE INF O}

\section{Article history:}

Received 28 July 2017

Received in revised form 19 September 2017

Accepted 20 September 2017

Keywords:

Dorsal root ganglion (DRG)

Regeneration

Conditioning lesion

Apoptosis

\section{A B S T RACT}

\begin{abstract}
In this study, it was aimed to prove the way of in vitro conditioned cells death. There is an increased axonal regeneration after a peripheral nerve is injured if it exposed to an earlier prior injury. The first injury causing the enhanced regeneration is called a conditioning lesion. In this study, Dorsal Root Ganglion primer cell culture was performed then neurons were conditioned in vitro with an effective and new method. It was observed that in vitro conditioned cells were regenerated much faster than control group cells but at the end of $48^{\text {th }}$ hour, they died. The cell death way of these in vitro conditioned neurons was determined by an in situ Cell Detection Kit Fluorescein and visualized by fluorescent microscopy. Finally, apoptotic cell deaths observed at in vitro conditioned neurons. This study is important for the continuity of enhanced regeneration capacity of conditioning lesion effect and neuronal survival and also it will provide the basis for new studies.
\end{abstract}

(C) 2017. Turkish Journal Park Academic. All rights reserved.

\section{Introduction}

When a peripheral nerve axotomized and if this same nerve then receives a second lesion regeneration, can be enhanced compared with that of nerves without previous lesion. This enhanced axonal regeneration is called "conditioning lesion effect". Conditioning lesion effect, was first demonstrated by McQuarrie and Grafstein (1973) as a result of the observed increase in the rate of regeneration of the axons in the sciatic nerve compared to that following the only one lesioned sciatic nerve (McQuarrie and Grafstein 1973). There are many studies about this enhanced regenerative effect of conditioning lesion. In these studies, it is observed that a conditioning lesion in vivo also increased the rate of neurite outgrowth in explants of sensory ganglia and cultures of sensory neurons in vitro (Hi-Tsai et al., 1994; Edström et al., 1996). In similar studies, it has been shown that these increases of regeneration occur in sympathetic neurons in

\footnotetext{
* Corresponding author.
}

Tel.: +0 432444 5065; fax: +0 4322251368

E-mail address: ekoguz@yyu.edu.tr ganglion explant and cell cultures (Shoemaker et al., 2005, 2006). In order to investigate this effect most of the studies were performed on nerve (usually sciatic or optic nerve) in vivo then in explant of ganglions and dissociated cell cultures in vitro, in our previous study, this effect was investigated by cell culture of the Dorsal Root Ganglion (DRG) and whole of the conditioning lesion experiments were performed in vitro so all neurons were conditioned; with this method, the changes that occur in neurons can be observed. It is shown that within the first 24 hours the axon regeneration were active and fast. After 24 hours, the regeneration speed began to decrease and even in vitro conditioned neurons began to die (Kaval Oğuz, 2009). Based on these findings, death pathway of conditioned cells that started regeneration fast and effective were investigated.

The development of multicellular organisms depends on cell division, maturation, and cell death. This equilibrium, called homeostasis, is necessary for the survival of multicellular organisms (Krysko et al., 2008, Bastian et al., 2013). Cell death 
generally occurs in two ways; Apoptosis and necrosis. Apoptosis in cells is a programmed death; a natural process for homeostasis, besides that necrosis is an unprogrammed death because of pathological or chemical damage (Ulukaya et al., 2011). Apoptosis, which is a physiological death pattern, also plays an important role in defense by ensuring stable cell proliferation, keeping the number of cells in tissues, destroying virus-infected cells, and remove dangerous cells (cancer cells) out of the way. In addition, apoptosis plays an important role in the elimination of unwanted cells in many tissues during embryonic development. One of the most significant examples is in the central nervous system; during development, neurons are proliferated in the large amount, this initial overproduction is then followed by cell deaths and only the neurons that make functional synaptic connections with target cells or tissues stay alive. (Cooper and Hausman, 2006; Lüleyap, 2008). Cells exposed to apoptosis typically exhibit well-defined morphological changes. These changes are the chromatin condensation, karyorrhexis (nuclear fragmentation) and apoptotic bodies in the plasma membrane (Elmore, 2007). Apoptosis is characterized by many biochemical criteria. These are the changes in mitochondrial membrane permeability, the release of mitochondrial proteins into the intermembrane space and the activation of caspases (Bauchier-Hayes et al., 2008; Krysko et al., 2008; Koff et al. 2015). All these morphological and biochemical markers make possible to distinguish apoptosis from other cell death patterns. Different methods are used to determine the presence of apoptosis. These are morphological methods, immunohistochemical methods, biochemical methods, immunological methods and array-based methods (Ulukaya et al. 2011). In this study, the morphology of in vitro conditioned cells were investigated by using the fast and efficient TUNEL (TdT-mediated dUTP-biotin nick endlabeling) method which is a kind of immunohistochemistry based method.

\section{Material and Methods}

Adult Balb-c mice aged 6-12 weeks were used in the experiment. Before remove the DRGs, animals were anestized by an I.P. injection of ketamin (100 mg/kg, Ketalar, Pfizer). L4-L5 DRGs were quickly and aseptically removed under a stereomicroscope. DRGs were trimmed off all attached nerves in cold RPMI 1640 medium (Sigma) and then ganglions were transferred to Neurobasal A medium (Invitrogen) containing 2\% B27 (Invitrogen), 2 nM Glutamax-I (Invitrogen), 100 units of penicillin, $100 \mathrm{mg}$ streptomycin, $250 \mathrm{ng}$ amphotericin B per $\mathrm{ml}$ (Sigma) and $100 \mathrm{U} / \mathrm{ml}$ collagenase (Sigma). DRGs were incubated at $37^{\circ} \mathrm{C}, 5 \% \mathrm{CO}_{2}$ in an incubator for 40 minutes, washed with Hank's buffered salt solution (Sigma) three times. Then DRGs were incubated with trypsin $(1 \mathrm{mg} / \mathrm{ml})$ in NBA-B27 for 15 mins and then triturated for about 10 minutes by gently and repeatedly pipetting through the tips of narrowing bores (from $2 \mathrm{~mm}$ diameter down) and finally a 26 gauge injector needle. After trituration, DNAse $(50 \mu \mathrm{g} / \mathrm{ml}$, Sigma) was added to cell suspension and incubated for 30 mins, on a custom made agitator vibrating horizontally at 50 $\mathrm{Hz}$. Then the neurons were harvested in pellet by spinning the suspension at $120 \mathrm{~g}$ for $3 \mathrm{mins}$ and they were resuspended in NBA-B27 supplemented with $10 \%$ fetal calf serum (Sigma) and $700 \mathrm{mg} / \mathrm{ml}$ trypsin inhibitor (Sigma). For selective isolations of the neurons, gradient centrifuge technique was used. For this, the cell suspension was carefully pipetted on top of a three-layer percol (Sigma) gradient $(60,35$ and $10 \%$ from bottom to top) prepared with NBA-B27 and spun at $3000 \mathrm{~g}$ for 20 mins in a centrifuge cooled down to $4{ }^{\circ} \mathrm{C}$. The neurons that were collected from $35 \%$ layer were washed with NBA-B27 and spun once more at $120 \mathrm{~g}$ for 3 mins then supernatant was discharted and pellet was re-suspended in 1 ml NBA-B27. (Cengiz et al. 2012). The cell suspension were seeded on silicon (WPI-Dow-corning) coated glass dish and conditioned in incubator for 3 days $\left(37 \mathrm{C}^{0}\right.$ and $\left.5 \% \mathrm{CO}_{2}\right)$. At the end of third day, after tirutiration of the suspension, cells were seeded $35 \mathrm{~mm}$ diameter glass bottomed Petri dishes (WPI), which had been previously coated with poly-L-lysine (Sigma) $\left(1.8 \mu \mathrm{g} / \mathrm{cm}^{2} 2\right.$ hours at RoomTemparature) and then laminin (Sigma) $\left(40 \mathrm{ng} / \mathrm{mm}^{2}\right.$, overnight at $\left.37^{\circ} \mathrm{C}\right)$. The preparations were kept in the incubator for 1 hour to let the neurons attach to the bottom of the dish and finally filled with NBA-B27 and returned to the incubator (Kaval Oğuz, 2009). To visualize the death of the neurons Propidium iodide (PI) was added culture medium of control group cells and in vitro conditioned cells. It is known that basic principle of PI in identifying viability is to determine whether the cellular membrane is degenerate or not, cells with degenerated membranes (dead cells) stain with PI and turn red, cells with intact membranes (alive cells) are not stained (Ulukaya et al. 2011).

In vitro conditioned cells were seeded Petri dishes after 48 hours, cells were fixed with 4\% paraformaldehyde for 15 min at room temperature. Cells were permeabilized with freshly prepared phosphate-buffered saline containing $1 \%$ triton X100 and $0.1 \%$ sodium citrate for 2 minutes on ice. Preparations were then incubated with $200 \mu$ l TUNEL reaction mixture (In situ Cell Detection Kit Flourescein-Roche) $60 \mathrm{~min}$ in dark, $37^{\circ} \mathrm{C}$ and humid environment (Geçit et al., 2014). Preparations were washed with PBS and imaged with flourescent time-lapse microscopy system (Cell observerZeiss).

\section{Results}

DRGs were removed and dissociated to neurons, while control group neurons were seeded Petri dishes, conditioned group neurons were seeded Petri dishes after 3 days of incubation. Neuronal survival of control cells (unconditioned) and in vitro conditioned cells were compared by staining Propidium Iodide and image with fluorescent cell observer (Zeiss) 48 hour after seeding. When the number of dead cells compared with the control group considerably higher in the in vitro conditioned group (Fig. 1A-B). It was also found that the control group cells maintained viability compared to cells 
conditioned in vitro but they started regeneration later.

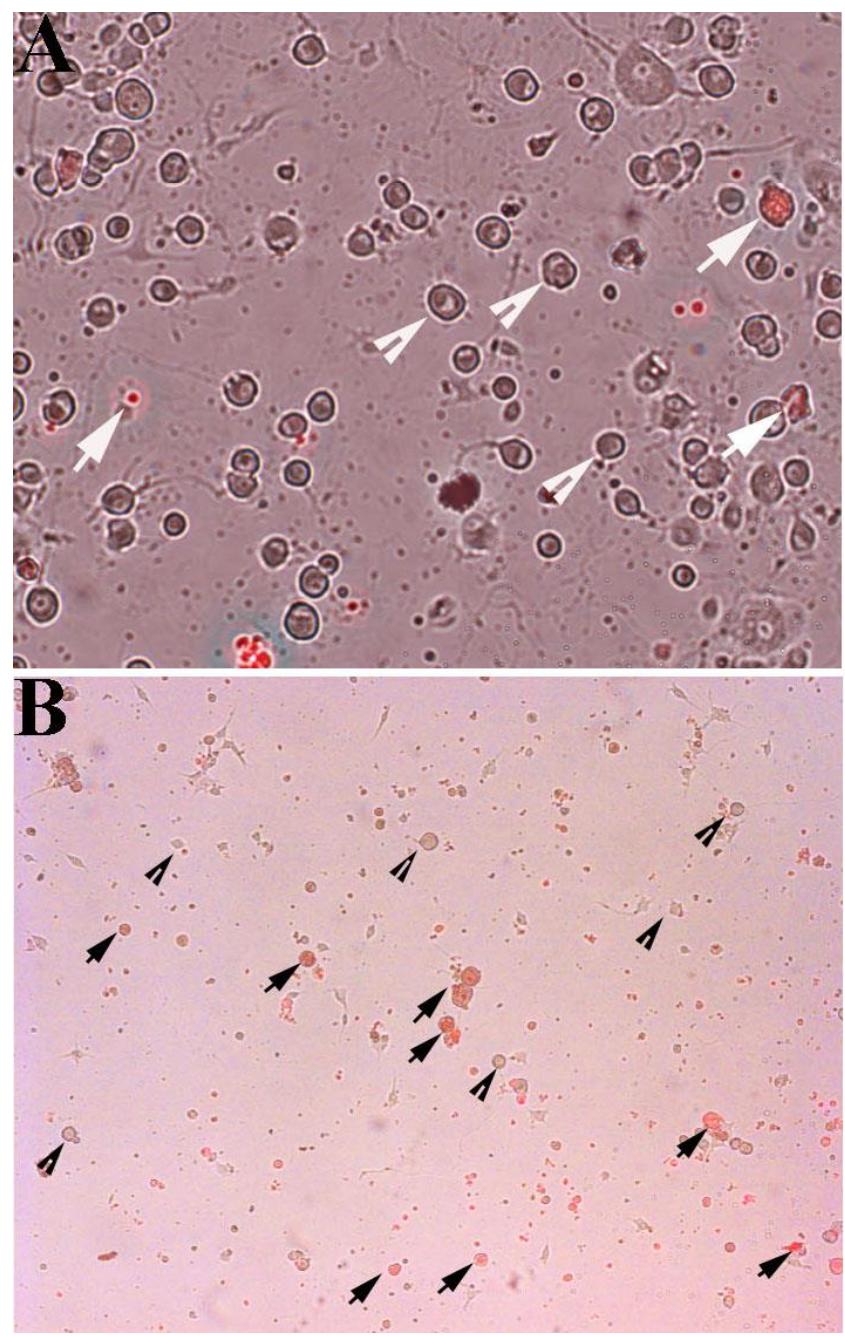

Figure 1. Neuronal survival of control cells (A) and in vitro conditioned cells (B) staining with Propidium Iodide. A. Control group of DRG cells, arrows indicates dead cells (they intake PI and stain red), arrowheads indicates alive neurons. B. In vitro conditioned DRG cells arrows indicates dead cells (they intake PI and stain red), arrowheads indicates alive neurons.

The in vitro conditioned cells were stained with the in situ Cell Detection Kit Fluorescein (Roche) and it is observed that the apoptotic cells were stained green. This result suggested that the in vitro conditioned cells were died by apoptosis (Fig.2AB).
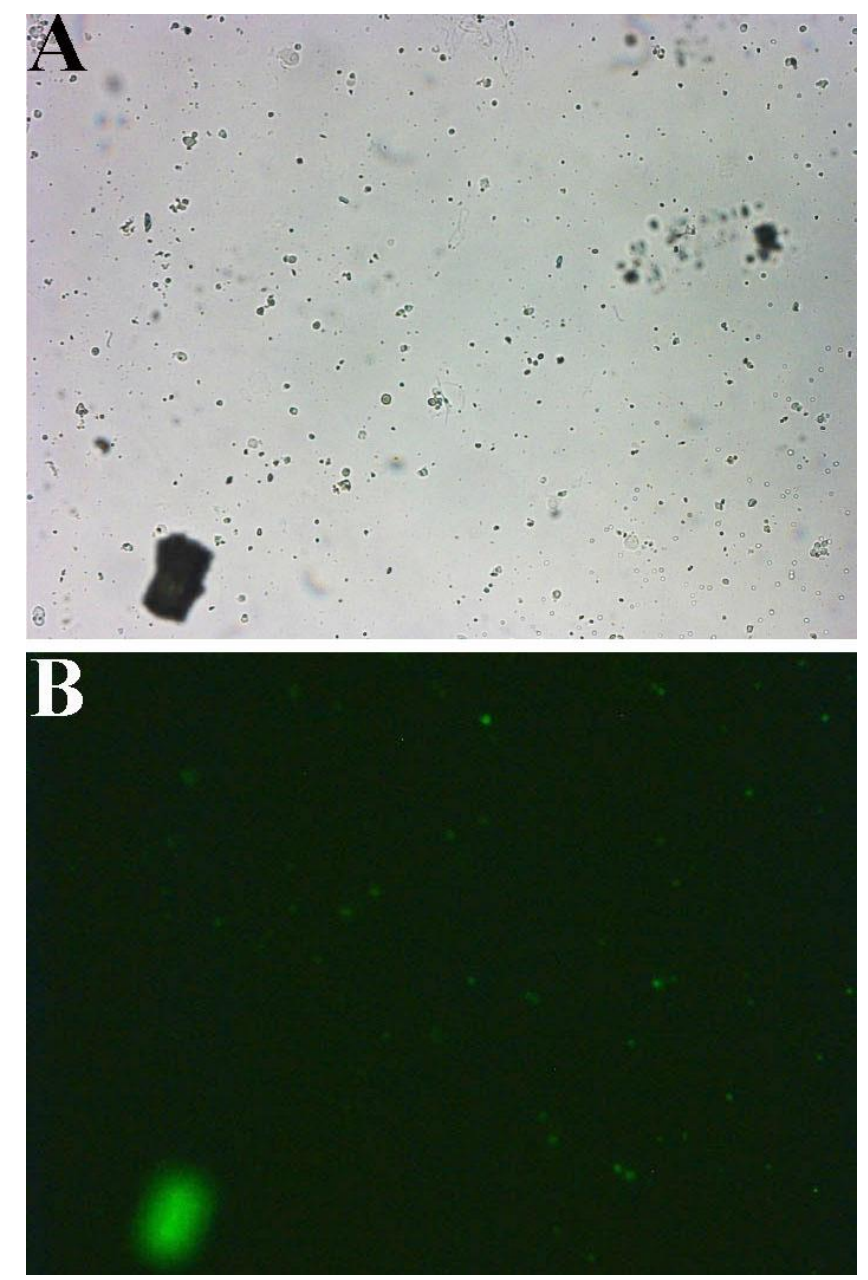

Figure 2. Apoptotic cells of in vitro conditioned DRG neurons. A. Phase-contrast image B. Fluorescent image apoptotic cells stained green.

\section{Discussion}

Regeneration is the renewal of tissue or cell loss that occurs after damage in living organisms. Regeneration in the nervous system occurs differently from other tissues; regeneration of nervous system does not mean the formation of new cells. Regeneration in nervous system occurs as axonal regeneration, after a nerve injury neurons revert back to elongation mode, extend their axons and make their contact with their targets again. While, this regeneration occurs highly effective in the peripheral nervous system, in adult central nervous system quietly reduced regeneration capacity (Dahlin, 2004; Doron-Mandel et al., 2015). Once a peripheral nerve has been damaged and then the same nerve is reinjured a second time, a faster and more effective regeneration is observed compared with the nerve injured once, this phenomenon is called "Conditioning lesion effect" (Zhang et al., 2004). Many studies have been carried out to 
search this effect, it is known that most of the sciatic nerve fibers last at L4-L5 Dorsal Root Ganglions (DRGs) because of this, these studies are focused on these DRG neurons. After a while sciatic nerve crush, L4-L5 DRGs were removed and observed in vitro in explants and dissociated cell cultures. (Cafferty et al., 2001; Cafferty et al., 2004; Liu and Snider 2001; Qiu et al., 2005). To search the mechanism of conditioning lesion effect, one week after the carotid nerve axotomy superior cervical ganglia were removed and done explant or dissociated cell culture (Shoemaker et al., 2005; Sachs et al., 2010). All these studies need an in vivo step which primarily provide the chance of an in vitro research only after the lesion which is applied on sciatic nerve in vivo. In this study, all of the conditioning lesion studies were performed in vitro and all neurons were conditioned and the death pathway of the in vitro conditioned neurons is investigated.

Programmed cell death or in other words, apoptosis, is an essential part of both normal development and disease in living organisms. In both embryogenesis and in pathological conditions it is necessary to investigate apoptosis mechanism and apoptosis inducing and regulating signals, this necessity encourages researchers to work on this issue (Guimaraes and Linden, 2004). Apoptosis, also known as nuclear death or programmed cell death, is the best-defined cell death pattern. Morphological and histochemical changes are observed in cells exposed to apoptosis, such as shrinkage, formation of bubbles, chromatin condensation, nuclear fragmentation, formation of apoptotic bodies, and exfoliation of the phosphatidylserine located on the inner surface of the cell membrane. These changes usually result in the activation of caspases, which are cysteine proteases that trigger cell suicide (Thornberry and Lazebnik, 1998; Ziegler and Groscurth 2004; Bredesen et al., 2006). Biochemical activation of apoptosis occurs by the intrinsic pathway, which exerts through the extrinsic pathway and mitochondria are formed by the activation of death receptors on the cell surface. The apoptotic process, which can be stimulated by either pathway, is accelerated by caspases (Van Cruchten and Van Den Broeck, 2002; Bredesen et al., 2006).

Cell death in the nervous system occurs physiologically during neurogenesis, but it occurs pathologically with neurodegenerative diseases such as trauma, ischaemia, Alzheimer, Parkinson, Huntington Disease. Apoptosis in neurons are induced by misfolded proteins, reactive oxygen and nitrogen species, mitochondrial damage, excessive calcium entry, excitotoxicity, activation of death receptors, withdrawal of trophic factors, and DNA damage to name a few (Bredesen et al., 2006). In this study, it is observed that in vitro conditioned neurons regenerate extremely but after 24 hour this regeneration rate decreased at the end of 48th hour cells started to die despite that in control group neurons regenerate later and at 48th hour they were alive. The observations with light microscopy shrinkage of neurons, blebbing of the plasma membrane, supported the hypothesis that the death pattern of these neurons might be apoptosis. For this purpose, the death pathway of these neurons was investigated by TUNEL method which provides determination of DNA breaks in situ and gives clear images of apoptotic cell death in a cell population. As a result, it was shown that these conditioned neurons which started to regeneration quickly and effectively were then died by apoptosis. We believe that this study will contribute to further studies in elucidating the treatment and mechanism of neurodegenerative diseases that occur in the nervous system and in terms of ensuring that the triggering effect of conditioning lesion on nerve regeneration.

\section{References}

Bastian, A. M., Yogesh T. L., and Kuraswamy, K. L., 2013. Various Methods Available for Detection of Apoptotic Cells- A Review. Indian Journal of Cancer. 50 (3), 274-283.

Bouchier-Hayes, L., Munoz-Pinedo, C., Connell, S., and Green, D.,R., 2008. Measuring Apoptosis at the single level. Methods, 44, 222-228.

Bredesen, D. E., Rao, R. V., and Mehlen, P., 2006. Cell Death in the Nervous System. Nature, 443(7113), 796-802.

Cafferty, W. B. J., Gardiner, N. J., Das, P., Qui, J., McMahon, S. B., and Thompson, S. W. N., 2004. Conditioning injury-induced spinal axon regeneration fails in Interleukin- 6 knock-out mice. The Journal of Neuroscience, 24, (18): 4432-4443.

Cafferty, W. B. J., Gardiner, N. J., Gavazzi, I., Powell, J., McMahon, S. B., Heath, J. K., Munson, J., Cohen, J., and Thompson, S. W. N., 2001. Leukemia Inhibitory Factor determines growth status of injured adult sensory neurons. The Journal of Neuroscience, 21 (18), 7161-7170.

Cengiz, N., Öztürk, G., Erdoğan, E., Him, A., and Kaval Oğuz, E., 2012. Consequences of Neurite Transection In Vitro. Journal of Neurotrauma, (29):2465-2474.

Cooper, G. M., and Hausman, R. E., 2006. Hücre Moleküler Yaklaşım, 3. Baskı. İzmir Tıp Kitabevi. İzmir. 579-582.

Dahlin, L., B., 2004. The biology of nerve injury and repair. Journal of the American Society For Surgery of The Hand, 3, 143-155.

Doron-Mandel, E., Fainzilber, M., and Terenzio, M., 2015. Growth Control Mechanisms in Neuronal Regeneration. FEBS Letters, 589(14), 1669-1677.

Edström, A., Ekström P. A., and Tonge, D. 1996. Axonal Outgrowth and Neuronal Apoptosis in Cultured Adult Mouse Dorsal Root Ganglion Preparations: Effects of Neurotrophins of Inhibition of Neurotrophin Actions and of Prior Axotomy. Neurocience, 75, 1165-1174

Elmore, S., 2007. Apoptosis: A Review of Programmed Cell Death. Toxicologic Pathology, 35(4), 495-516.

Geçit, İ., Kavak, S., Kaval Oğuz, E., Pirincci, N., Güneş, M., Kara, M., Ceylan, K., Kaba, M., and Tanık, S., 2014. Tissue Demage in Kidney, Adrenal Glands and Diaphram Following Extracorporeal Shock Wave Lithotripsy. Toxicoly and Industrial Health, 30 (9), 845-850.

Guimaraes C. A., and Linden R., 2004. Programmed Cell Death Apoptosis and Altenative Deathstyles. Europian Journal of Biochemistry, 271, 1638-1650.

Hu-Tsai, M., Winter, J., Emson, P. C., and Woolf, C., 1994. Neurite outgrowth and GAP 43 expression in cultured adult rat dorsal root ganglion neurons: effects of NGF or prior peripheral axotomy. Journal of Neuroscience Reserch, 39, 634-645.

Kaval Oğuz, E., 2009. Searching of Conditioning Lesion Effect and Its 
Mechanism In Nerve Regeneration. PhD Thesis. Yüzüncü Yıl University, Van. 187.

Koff, J. L., Ramachandiran, S., and Bernal-Mizrachi, L., 2015. A time to Kill: Targeting Apoptosis in Cancer. International Journal of Molecular Science, 16, 2942-2955.

Krysko, D. V., Berghe, T.V., D’herde, K., and Vandenabeele, P., 2008. Apoptosis and Necrosis: Detection, discrimination and phagocytosis. Methods, 44, 205-221.

Liu., R. Y., and Snider, W.D., 2001. Different signalling pathways mediate regenerative versus developmental sensory axon growth. Journal of Neuroscience, 21, RC164

Lüleyap, H. Ü., 2008. Moleküler Genetiğin Esasları, Nobel Kitabevi, Adana. 292-299.

McQuarrie, I. G., and Grafstein, B., 1973. Axon Outgrowth Enhanced by a previous Nerve Injury. Archives of Neurology, 29, 53-55.

Qui, J., Cafferty, W. B., McMahon, S. B., and Thompson, S. W., 2005. Conditioning injury-induced spinal axon regeneration requires signal transducer and activator of transcription 3 activation. Journal of Neuroscience, 25, 1645-1653.

Sachs, H. H., Rohrer, H., and Zigmond, R. E., 2010. The Conditioning Lesion Effect on Sympathetic Neurite Outgrowth is Dependent on gp130 Cytokines. Experimental Neurology, 223, 516-522.
Shoemaker, S. E., Sachs, H. H., Vaccariello, S. A., and Zigmond, R. E. 2005. A Conditioning Lesion Enhances Sympathetic Neurite Outgrowth. Experimental Neurology, 194, 432-443.

Shoemaker, S. E., Sachs, H. H., Vaccariello, S. A., and Zigmond, R. E., 2006. Reduction in nerve growth factor availability leads to a conditioning lesion-like effect in sympathetic neurons. Journal of Neurobiolgy, 66, 1322-1337.

Thornberry, N. A., and Lazebnik, Y., 1998. Caspases: enemies within. Science, 281, 1312-1316.

Ulukaya, E., Acilan, C., Ari, F., İkitimur, E., and Yilmaz, Y. A., 2011. Galance at the Methods for Detection of Apoptosis Qualitatively and Quantatively. Turkish Journal of Biochemistry, 36(3), 261-269.

Van Cruchten, S., and Van Den Broeck, W., 2002. Morphological and Biochemical Aspects of Apoptosis, Oncosis a Necrosis. Anatomia Histologia Embryologia, 31, 214-223.

Zhang, L., Palmer, R., and McClellan, A. D., 2004. Conditioning lesion enhance axonal regeneration of descending brain neurons in spinalcord-transected larval lamprey. The Journal of Comparative Neurology, 478. 395-404.

Ziegler, U., and Groscurth, P., 2004. Morphological Features of Cell Death. Physiology, 19, 124-128. 